\title{
Examining drivers of green appliance adoption using two theories among middle class consumers
}

\author{
Nombulelo Dilotsotlhe \\ Department of Marketing Management \\ School of Consumer Intelligence and Information Systems \\ University of Johannesburg, Johannesburg, South Africa \\ Helen Duh Inseng \\ Department of Marketing, School of Economic and Business Sciences \\ University of the Witwatersrand, Johannesburg, South Africa
}

\section{Key words}

Green appliances; theory of consumption values; theory of planned behaviour; black middle class; attitudes; adoption behaviour.

\begin{abstract}
The rapid growth of middle-class consumers in emerging markets like South Africa is often characterised by high energy consumption, driven by demand for household appliances. As green appliances can reduce energy consumption, this study (1) examined South African black middle class consumers' attitudes and adoption behaviour of green appliances; (2) integrated the theories of consumption value and planned behaviour for a richer explanation of attitudes and behavioural intention (BI) regarding green appliances; and (3) assessed whether BI and perceived behavioural control (PBC) translate into actual adoption. Data was quantitatively gathered from 500 respondents who were aware of green appliances, displayed the intention to buy green appliances and had bought green appliances. Data was analysed using partial least squares structural equation modelling.

Findings showed that respondents hold a strong positive attitude towards green appliances $(M=5.8)$, which was significantly driven by functional, emotional, and epistemic values. Attitude, social value and PBC drove BI which, with $P B C$, influenced adoption. The integrated model explained far greater percentage of attitude (81\%) and BI (83.4\%) compared to studies applying only one theory.

The original value lies in the sampling of consumers, who are working and capable of buying green appliances. Previous studies have mainly used students, who lack purchasing power.

The integrated model makes theoretical implication by providing greater explanatory power of green product adoption. Practically, from their positive attitudes towards green appliances and adoption behaviour, governmental/environmental interest groups can use the large and influential black middleclass as opinion leaders to promote green product use.
\end{abstract}

Corresponding author: Nombulelo Dilotsotlhe

Email addresses for the corresponding author: ndilotsotlhe@uj.ac.za

First submission received: $11^{\text {th }}$ May 2020

Revised submission received: $30^{\text {th }}$ June 2020

Accepted: 2nd July 2020

\section{Introduction}

The adoption of lower energy consuming lifestyles has become imperative for resources and environmental sustainability (Pothitouetal, 2016; UNEP, 2015). This is particularly the case in emerging markets such as South Africa, where the economic aspirations of billions of people, especially the rapidly growing middle class consumers, are often facilitated by "unprecedented levels of energy consumption" (Smil, 2013). Consequently, electricity demand in countries like South Africa is fast outstripping supply (UNEP, 2014; Sonneberg, Erasmus and Schreuder, 2014). Compounding this problem is the increased demand for household appliances by growing middle class consumers who have a "proportionally higher share in the average ecological footprint" (Sonneberg et al., 2014). 
Black middle-class consumers are growing faster in size and influence in South Africa compared to other middle-class consumers. Between 2004 and 2016, this segment rose steeply from 1.74 million to 5.61 million (University of Cape Town [UCT] Unilever Institute, 2016). Also termed 'Black Diamonds', the black middle class is seen as the largest driver of South Africa's economic growth (Steyn, 2013), with nearly $65 \%$ of these consumers owning their own homes (Kroeker, 2014). This rate of home ownership comes with the demand for household goods and appliances. In terms of home appliances, the UCT Unilever Institute's 2016 Report revealed that in 2004, black middle class consumers' ownership of dish washers, home computers, DVD players, washing machines and microwaves was 3\%, 19\%, 30\%, 24\% and $60 \%$ respectively. By 2012, with the exception of dish washers, the segment's ownership of these items doubled by $4 \%, 45 \%, 63 \%, 58 \%$ and $92 \%$ respectively. While these increases in demand for home appliances are attractive to the manufacturers and marketers, their strain on energy consumption is a concern.

Cognisant of energy consumption concerns and the environmental impact of home appliances, brands like Defy, LG and Samsung, which are key role players in the South African home appliance industry, are designing green appliances with lower water and energy consumption. This is in addition to the usual value-for-money, aesthetically pleasing and feature-rich appliances for consumers to choose from (Euromonitor International, 2013). The factors that drive consumers, especially the black middle class, to choose and adopt green options often perceived as being more expensive (Zhang, Xiao, and Zhou, 2020) need investigation.

The green products adoption as Yadav and Pathak (2017) report, is exhibited by the use of green/environmentally friendly products, the use of organic products, proper waste disposal management or recycling etc. In this study, it is construed in terms of the purchase and use of green appliances. Numerous studies have examined green product adoption, for example, in Asia (Biswas and Roy, 2015; Lin and Huang, 2012; Huang, Lin, Lai and Lin, 2014; Yadav and Pathak, 2017; Zhang et al., 2020), United State of America, (Matthes, Wonneberger and Schmuck, 2014; Barber, Bishop and Gruen, 2014), Europe (Kanchanapibul, Lacka, Wang and Chan, 2014; Faure and Schleich, 2020) and Australia (Tan, Johnstone and Yang, 2016). These studies have examined segments, profiles, drivers, and barriers to green products adoption. Most have either mainly and independently used the theory of planned behaviour (TPB), the diffusion of innovation theory (DOI) or the theory of consumption values (TCV) to explain the intention to adopt green products. Actual adoption has rarely been examined (Yadav and Pathak, 2017).

Given the complexity of adoption and purchase decision, especially for non-conventional items such as green products, there is a need to integrate theories for a richer explanation of decisions. Chen (2014), for example, integrated the TPB and the DOI theories. The integration explained up to $76 \%$ of variance in green products behavioural intention. This can be compared to Taylor (2015) who, by using the DOI theory alone, could only explain $26.7 \%$ of green product behavioural intention. Beyond just intention, however, the present study integrated the TPB and the TCV to explain South African black middle-class consumers' attitudes, intention, and actual adoption of green appliances (i.e., washing machines, fridges, geysers, and freezers). Specifically, three objectives were addressed: (1) to assess South African black middle class consumers' attitudes towards green appliances and the extent of their adoption; (2) to examine the explanatory power of Sheth, Newman and Gross's (1991) TCV and Ajzen's (2005) TPB with regard to green appliance attitude and behavioural intention; and (3) to test the impact of behavioural intention and perceived behavioural control on actual adoption.

\section{Theoretical framework and proposed hypotheses}

\subsection{Theory of planned behaviour and theory of consumption values}

The TPB posits that an individual's behavioral intention to perform (BI) - or not to perform - a given behaviour is the most fundamental determinant of that action occurring (Ajzen, 2005).

$\mathrm{BI}$ can be defined as "an indication of individual's readiness to perform a given behaviour" (Yadav and Pathak, 2017). BI is driven by attitude, social norms, and perceived behavioural control, all of which are interrelated (Ajzen, 2005). Attitude denotes an individual's overall positive or negative evaluation of engaging in a particular behaviour. It comprises three elements - affective (e.g. like/dislike), cognitive (beliefs and ideas) and conative (tendency to act in a particular way). Subjective norm refers to an 
individual's perceptions of social pressure from important referents to perform a behaviour. Perceived behavioural control (PBC) refers to individuals' perceived level of control (in terms of ability and possession of resources) over performing a behaviour (Ajzen, 2005). TPB is widely considered to be one of the most influential theories for predicting both behavioural intention and actual behaviour for a wide range of products and services (Chen and Tung, 2014).

The TPB is also known as a key theoretical lens for predicting green or pro-environmental behaviour (Zhang et al., 2020). More specifically, the theory has been validated in several studies investigating recycling behaviours (Wan, Cheung and Shen, 2012), green hotels and restaurants (Chen and Tung, 2014), energy-efficient products (Ha and Janda, 2012; Zhang et al., 2020), green products (Chen and Peng, 2012) and organic food choices (Kim and Chung, 2011). However, although the robustness of the TPB has been proven in many studies, its explanatory power is limited as aforementioned. Moreover, knowledge of the drivers of the attitude, which is an important predictor of behavioural intention (Ajzen, 2005; Paul, Modi, and Patel, 2016) is lacking.

Whilst attitudes are built after favourable or unfavourable evaluations of a particular behaviour (Chen and Tung, 2014), they can also be based on the evaluation of a particular product (Liao, Shen and Shi, 2020). Since the favourability of the attitude would depend on the perceived benefits of the product (Zhang et al., 2020), we propose that attitudes towards green appliances will be formed by the perceived benefits derived from green appliances. The TCV specifies five values which not only influence attitude, but also influence choice (see Figure 1 below). Following Sheth et al. (1991) descriptions, these five values can be described as follows:

Functional value refers to the ability of a product or service to satisfy the consumer's utilitarian needs.

Social value is the extent to which individuals sacrifice self-control as a way of enhancing behaviour congruent with a preferred social group.

Emotional value relates to the perceived utility acquired from an alternative's capacity to arouse feelings or affective states.

Epistemic value refers to the perceived utility acquired from an alternative's capacity to arouse curiosity, provide novelty and satisfy a desire for knowledge.

Conditional value is described as the consumer's satisfaction with purchase decisions that are triggered by a set of situational factors in the marketplace.

The TCV has assisted researchers and practitioners to understand why consumers behave in a certain way towards the adoption of certain products (Biswas and Roy, 2015). For example, Lin and Huang (2012) used the TCV to identify factors influencing consumers' choice of green products. They found that choice was determined by the emotional, epistemic and conditional values whereas consumption behaviour was determined by the functional and epistemic values. Given these findings, and to increase the predictive power, this study integrated the TCV and TPB to formulate the hypotheses.

\subsection{Hypotheses}

Functional value and attitudes

Attitude towards environmental products has been described as a sum of beliefs, impressions, affect and predispositions that a person holds about environmental issues and activities (Liao et al., 2020). This attitude, which can be either positive or negative, is formed when there is a perception of the functional value of a product. Functional value can be defined as "the consumer's perception of how well a product/brand will fulfil utilitarian needs, such as the assurance of product quality and performance" (Albrecht, Backhaus, Gurzki and Woisetschlager, 2013). In the context of green appliances, Zhang et al. (2020) define functional value in terms of the product's ability to lessen resource depletion (e.g., water and electricity), reduce harmful emissions, protect the environment and promote a lower-carbon lifestyle. Consumers who are impressed with these functional abilities develop favourable attitudes towards purchasing green appliances (Zhang et al., 2020).

Conceptualising functional value in terms of product quality and price paid for it, Biswas and Roy (2015) found that it impacted the purchase of recycled products and even the behavioural intention to pay higher prices associated with green products. Maheshwari and Malhotra (2011) and Tsay (2010) also established that functional value has a positive influence on the purchase of green products. According to 
Barber et al. (2014), green consumers are typically driven by the functional value of green products, which should positively impact their attitude. Hence, the following hypothesis is proposed:

$\mathrm{H}_{1}$ : Functional value will positively influence attitudes towards green appliances

\section{Emotional value and attitudes}

Emotional value can be described as the "utility derived from the feelings or affective states that a product generates" (Sweeney and Soutar, 2001). It also includes the perceived feeling or emotion (e.g., comfort, worry, pleasure) derived from the pre-decision to buy a particular product. For example, consumers may plan to buy energy-saving appliances with the comfort of knowing that they would save on water and electricity costs. This would be particularly pertinent in South Africa, where such costs increase yearly. Other consumers may plan to buy green appliances with the pleasure that these products will be environmentally friendly. These attributes of green appliances lead to a positive attitude towards buying the green appliances (Zhang et al., 2020). Koenig-Lewis, Palmer, Dermody and Urbye (2014) also found that the intrinsic feelings of doing something good both for one's financial and psychological wellbeing and that of the environment influence consumer attitude. Previous research has found that consumers with positive emotional values make enjoyable and receptive green purchase decisions as these strengthen their belief and feelings that they are behaving responsibly to protect the environment (Biswas and Roy, 2015; Lin and Huang, 2012). Hence, the following hypothesis is proposed:

\section{$\mathrm{H}_{2}$ : Emotional value will positively influence attitudes towards green appliances}

Conditional value and attitudes

While emotional value is triggered intrinsically, conditional value is triggered by extrinsic circumstances, which prompt the need to choose alternatives (Woo and Kim, 2019). Environmental threats can enhance the propensity of consumers to choose environmentally friendly products, develop positive attitudes and act in a pro-environmental manner (Lin and Huang, 2012). Environmental problems which may enhance conditional value include climate change, global warming, pollution, the depletion of fossil fuels as well as water and electricity shortages (Jamilah, Grigore and Stancu, 2012). When consumers understand the implications of their consumption behaviour, it is expected that a feeling of moral obligation to do something about it will emerge and trigger pro-environmental attitudes and behaviours (Gadenne, Sharma, Kerr and Smith, 2011). In South Africa, frequent blackouts and water shortages have been felt by many and should, in principle, build more positive attitudes towards green appliances. Hence, the following hypothesis is proposed:

\section{$H_{3}$ : Conditional value will positively influence attitudes towards green appliances}

Epistemic value and attitudes

Teng (2019) views epistemic values as "the benefit acquired from a product's capacity to provide novelty or arouse curiosity to meet a person's need for novelty, knowledge, or variety seeking". The author further report that the most important epistemic value consumers seek in products is innovativeness. Thus, beyond the functional, conditional, and emotional values that drive consumers' attitudes, Xiao (2005) suggests that attitudes are also influenced by epistemic values. For green products, Mostafa (2009) and Suki (2013) contend that curiosity about a product's environmental contribution has a significant impact on green consumers' attitudes and behaviour. Lin and Huang (2012) note that the epistemic value of green products in terms of product characteristics, product design and novelty significantly influence consumers' choice. Hence, the following hypothesis is proposed:

\section{$H_{4}$ : Epistemic value will positively influence attitudes towards green appliances}

Social value, attitudes, and behavioural intention

The quest to enjoy social value in terms of social identification, approval, symbolism and belonging (Koenig-Lewis et al., 2014) can influence product attitude and consumption behaviour. In particular, social identification plays a key role in buying behaviour as it enhances approval from an esteemed reference group (Bartels and Reinders, 2010). Similarly, Dhurup (2012) uses the term 'in-group association' to suggest the extent to which individuals sacrifice self-control as a way of conforming with the views of a preferred social group. For instance, the surge in environmental concern among social groups and the 
formation of environmental clubs confirms the importance of social values in promoting proenvironmental attitudes and behaviour (Lin and Huang, 2012). For green appliances, Zhang et al. (2020) contend that "the more consumers feel that the purchase and use of energy-saving appliances helps them to demonstrate their image and win praise", the more they will develop favourable attitude towards the purchase of green appliances.

In addition to attitude, social value is also recognised as a predictor of consumers' intention to purchase green products (Biswas and Roy, 2015). Wahid, Rahbar and Shyan (2011) concur, stating that social value is a proxy for subjective norm and is therefore one of the dominant factors influencing behavioural intention. Hence, the following hypotheses are proposed:

$H_{5}$ : Attitude towards green appliances is positively influenced by social value.

$H_{6}$ : Social value will positively influence behavioural intention towards green appliances

Attitudes and behavioural intention

The more favourable a person's attitude towards some considered behaviour, the more likely that the person will engage in that behaviour (Cherian and Jacob, 2012). Pro-environmental behaviour is contingent on nurturing and enforcing environmental attitudes (Zabkar and Hosta, 2013). Ajzen (1991) further suggests that a consumer's attitude towards a certain behaviour predicts that person's intention to carry out that behaviour. However, attitude occurs not only towards a behaviour, as Ajzen (1991) suggests; it can also occur in terms of an individual's consistent favourable or unfavourable evaluation, feeling or tendency towards a product or service (Suki, 2013). Woo and Kim (2019) found that attitudes towards green food, for example, positively impacted behavioural intention. In this context, it is expected that positive attitude towards green appliances will influence behavioural intention. Hence, the following hypothesis is proposed:

$H_{7}$ : There is a positive relationship between attitudes towards green appliances and the intention to purchase them.

Perceived behavioural control (PBC), behavioural intention and adoption behaviour

The TPB posits that individuals' perceived possession of the resources (i.e., time, money and the skill or ability) to perform a particular behaviour (i.e., PBC) will either directly influence their adoption of the behaviour, or indirectly through their intentions to perform the task (Ajzen 1991). This is particularly true for green appliances which are perceived to be expensive, unconventional and may require new skills to operate the innovative features (Zhang et al., 2020). While functional value is the perception of the product's quality and price, PBC assesses the ability to pay the price. A number of studies have shown that PBC positively impacts intention in various green contexts, such as recycling (Yeow, Dean and Tucker, 2014), conservation (Albayrak, Aksoy and Caber, 2013), green hotels (Chen and Tung, 2014) and green products in general (Moser, 2015). However, the relationship between PBC and actual adoption has been rarely empirically tested.

Considering Ajzen's (2005) proposition that PBC positively relates to both behavioural intention and actual behaviour, the current study tests these relationships. In terms of the direct relationship between behavioural intention and adoption behaviour as the TPB proposes, Lai and Cheng (2016) in Hong Kong and Yadav and Pathak (2017) in India have empirically proven the positive relationship. Hence, the following hypotheses are proposed:

$H_{8}$ : $P B C$ positively influences behavioural intention to purchase green appliances.

$\mathrm{H}_{9}$ : $P B C$ positively influences the adoption of green appliances.

$H_{10}$ : There is a positive relationship between behavioural intention and actual adoption of green appliances. 
The relationships hypothesised in this study are presented in Figure 1 below.

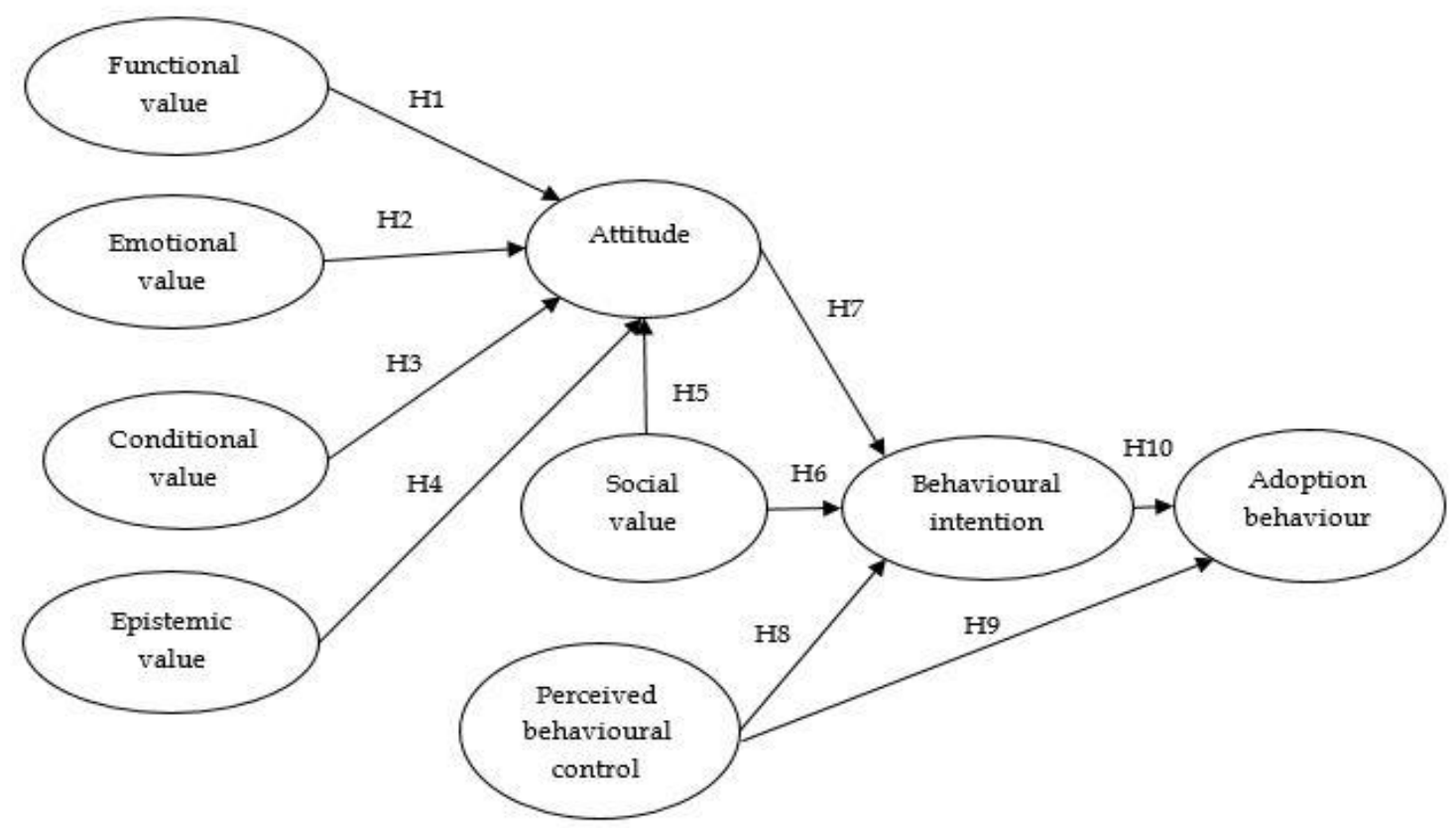

Figure 1: The Conceptual Model

\section{Research methodology}

\subsection{Sample}

Considering that the study tests a conceptual model and hypotheses, a quantitative design was appropriate. Quantitative data was collected through a face-to-face survey from black middle-class intentional users and actual users of green appliances. Intentional users are respondents who have positive attitudes and beliefs about the value of green appliances but are yet to buy them. Actual users were those who had bought appliances. These two types of users were distinguished through three screening questions which verified the respondents' awareness of green appliances, their intention to use them and their actual use of these appliances. The two user types were studied as behavioural intention was one of the constructs being investigated. The respondents who qualified were surveyed in the Gauteng Province as more than $66 \%$ of the black middle class resides in this province. The province is also regarded as the economic hub of South Africa (UCT Unilever Institute, 2016).

The data was collected by Ramsay Research Media, a professional research company with a database of middle-class consumers of all races. Ramsay has been collecting data for the UCT Unilever Institute of Strategic Marketing for numerous studies on the South African black middle class. A twostage stratified probability sampling technique was applied. The first stage involved dividing the Gauteng list of black middle-class consumers into 12 suburbs of high-, middle- and low-income earners. Of these 12 suburbs, seven were identified as having more middle-class consumers. The second stage involved using simple random sampling to draw the sample elements from each level with the help of Hawkins and Tull's (1993) random numbers. This guarantees sampling efficiency since it increases representativeness (Saunders, Lewis, and Thornhill, 2012). Respondents were contacted to agree to either a meeting at their workplace or any other place convenient to them for a face-to-face, self-administered questionnaire. Faceto-face questionnaire administration increases the response rate as opposed the online surveys (Saunders et al., 2012).

\subsection{Measures and analysis method}

The scales used to measure the constructs were adapted from previous studies with reliable measures (i.e., Cronbach's alpha of $\geq 0.7$ ). The sources of the scale and the items used to measure the constructs are shown in Table 1. 
Table 1: Constructs, Items, and their Sources

\begin{tabular}{ll}
\hline Constructs & Items \\
\hline Functional & FV1 Green appliances are of good quality. \\
value & FV2 Green appliances are well made. \\
& FV3 Green appliances have an acceptable standard of quality. \\
& FV4 Green appliances offer value for money. \\
& FV5 Green appliances perform reliably. \\
& FV6 Green appliances perform their functions of saving water \\
& and electricity for a long time.
\end{tabular}

Source

Biswas and Roy (2015)

Lin and Huang (2012)

Sheth et al. (1991)

Social value
SV1 Purchasing a green appliance causes/would cause me to be
admired.
SV2 Purchasing green appliances makes/would make a good
impression of me.
SV3 Purchasing green appliances improves/would improve the
way I am perceived.
SV4 Most people who are important to me expect/would expect
that I buy green appliances.

Emotional value

EMV1 Buying green appliances feels/would feel like making a good personal contribution to something better.

EMV2 Buying green appliances feels/would feel like the morally right thing to do.

EMV3 Buying green appliances makes/would make me feel like a better person.

EMV4 Buying green appliances makes/would make me feel good.

Conditional CV1 I buy/would buy green appliances when my financial value conditions are good.

CV2 I buy/would buy green appliances when there is a subsidy for green products.

CV3 I buy/would buy green appliances when there are discount prices for them.

CV4 I buy/would buy green appliances when they are available.

Epistemic value
EV1 Before buying green appliances, I obtain/would obtain substantial information about the different makes and models of the products.

EV2 I require/would require a great deal of information about the different makes and models before buying green appliances. EV3 I am willing to ask for new information about green appliances.

EV4 I like/would like to search for new and different types of green appliances.

Attitudes
AT1 I feel that green appliances' environmental conservation claims are generally trustworthy.

AT2 I feel that green appliances' environmental protection reputation is generally reliable.

AT3 Buying green appliances is/would be a good idea for me and the environment.

AT4 Buying green appliances is/would be a worthwhile purchase decision.

AT5 I have a favourable attitude towards purchasing a green version of products.

AT6 If I had to choose between green appliances and conventional ones, I would prefer the green version.
Choi and Johnson (2019)

Wang, Liu, and Qi (2014)

Biswas and Roy (2015)

Sheth et al. (1991)

Suki (2013)

Sheth et al. (1991)

Chen and Tung (2014) 


\begin{tabular}{|c|c|c|}
\hline $\begin{array}{l}\text { Perceived } \\
\text { behavioural } \\
\text { control }\end{array}$ & $\begin{array}{l}\text { PB1 I believe that I have the financial ability to purchase green } \\
\text { appliances. } \\
\text { PB2 If it were entirely up to me, I am confident that I would } \\
\text { purchase green appliances. } \\
\text { PB3 I see myself as capable of purchasing green appliances in } \\
\text { future. } \\
\text { PB4 I have resources to purchase green appliances. } \\
\text { PB5 I have the time to purchase green appliances. } \\
\text { PB6 Green appliances are generally available in the shops where } \\
\text { I usually do my shopping. }\end{array}$ & $\begin{array}{l}\text { Laurenti and Acuna (2020) } \\
\text { Moser (2015) }\end{array}$ \\
\hline $\begin{array}{l}\text { Behavioural } \\
\text { intention }\end{array}$ & $\begin{array}{l}\text { BI1 I intend to start/continue buying green appliances because } \\
\text { of their environmental benefits. } \\
\text { BI2 I will consider switching to green appliances for ecological } \\
\text { reasons. } \\
\text { BI3 I expect to start/continue purchasing green appliances in the } \\
\text { future because of their positive environmental contribution. } \\
\text { BI4 I definitely want to purchase green appliances in my next } \\
\text { purchase. }\end{array}$ & Laurenti and Acuna (2020) \\
\hline $\begin{array}{l}\text { Adoption } \\
\text { behaviour }\end{array}$ & $\begin{array}{l}\text { AB1 I make a special effort to buy green appliances. } \\
\text { AB2 I have switched to buying green appliances because of the } \\
\text { environmental benefits. } \\
\text { AB3 When I have a choice between the same types of products, I } \\
\text { purchase the ones that use less electricity and are less harmful to } \\
\text { the environment. } \\
\text { AB4 I make a special effort to buy home appliances that are } \\
\text { green or environmentally friendly. }\end{array}$ & $\begin{array}{l}\text { Chen and Tung (2014) } \\
\text { Ha and Janda (2012) }\end{array}$ \\
\hline
\end{tabular}

The respondents rated the items on a 7 -point Likert scale, where $1=$ strongly disagree and $7=$ strongly agree. A 7-point scale was preferred as previous studies have used the same scale and its reliability and validity can be reasonably compared across cultures.

A pilot study involving 30 respondents was first conducted. After testing the constructs' reliability and validity, the wording of some items was adjusted, and several items were deleted to improve construct reliability for the main study. For the main study, a total of 600 questionnaires was distributed to the respondents. Five hundred questionnaires were fully completed, yielding a response rate of $83.3 \%$. The 500 respondents fell within the minimum sample size of 200-500 to conduct structural equation modelling (Kline, 2011).

Data analysis started with descriptive statistics to obtain the constructs' and respondents' characteristics. Confirmatory factor analysis (CFA) was then conducted to assess the measurement model. We used Harman's one-factor test that Podsakoff, MacKenzie, Lee and Podsakoff (2003) propose to test common method variance (CMV). This was done by conducting exploratory factor analysis (EFA) with all of the items after specifying a one-factor model. From the one-factor solution which was unrotated, as suggested by Podsakoff et al. (2003), a variance explained of $40 \%$ was obtained. Since this figure was less than $50 \%$, it indicated the absence of CMV (Podsakoff et al., 2003). Partial least squares structural equation modelling (PLS-SEM) was the main analysis method used to test the conceptual model and the hypotheses. This was done using SmartPLS version 3.2.7. PLS-SEM was preferred over covariance-based SEM (CB-SEM) as it has better predictive ability, especially with small sample sizes and large models (Garson, 2016). While CB-SEM is optimal for parameter accuracy, PLS-SEM is optimal for prediction accuracy (Hair, Hult, Ringle and Sarstedt, 2017).

4. Results

\subsection{Profile of respondents}

The respondents comprised $53.8 \%$ females and $46.2 \%$ males. About $80 \%$ of the respondents were within the working ages of 26-60 years old, compared to $10 \%$ who were within the young adults ages of 
18-25 years old. Those employed constituted $93.8 \%$ while $2.6 \%$ were students and $3.6 \%$ were retired. Having up to $80 \%$ of the respondents within working age and $93.8 \%$ employed predicted their capability of buying green appliances. This was further supported by $88.4 \%$ of respondents reporting that they earned between R15,000 and R49,999+ $(\$ 1,026-\$ 3,420+)$. Earning this range of income qualified these consumers as middle class, which would have been made possible by the fact that up to $90.8 \%$ held between high school and master's qualifications. With these levels of education, awareness and use of green appliances would be likely.

\subsection{Measurement model}

\subsubsection{Mean, validity, and reliability}

The reliability of the constructs was tested using Cronbach's alpha and composite reliability, while the validity was assessed with factor loadings and average variance extracted (AVE) for convergent validity and correlation matrix for discriminant validity. The results are shown in Tables 2 and 3 below.

Table 2: Test of Reliability and Convergent Validity

\begin{tabular}{|c|c|c|c|c|c|}
\hline Constructs and items & $\begin{array}{l}\text { Factor } \\
\text { loading }\end{array}$ & Mean & Cronbach's alpha & Composite reliability & $\begin{array}{l}\text { Average variance } \\
\text { extracted }\end{array}$ \\
\hline Adoption behaviour & & 6.09 & 0.984 & 0.987 & 0.926 \\
\hline AB1 & 0.964 & & & & \\
\hline AB2 & 0.962 & & & & \\
\hline AB3 & 0.948 & & & & \\
\hline AB4 & 0.977 & & & & \\
\hline AB5 & 0.963 & & & & \\
\hline AB6 & 0.958 & & & & \\
\hline Attitude & & 5.80 & 0.952 & 0.962 & 0.807 \\
\hline AT1 & 0.894 & & & & \\
\hline AT2 & 0.914 & & & & \\
\hline AT3 & 0.889 & & & & \\
\hline AT4 & 0.900 & & & & \\
\hline AT5 & 0.907 & & & & \\
\hline AT6 & 0.884 & & & & \\
\hline Behavioural intention & & 5.78 & 0.930 & 0.950 & 0.827 \\
\hline BI1 & 0.921 & & & & \\
\hline $\mathrm{BI} 2$ & 0.920 & & & & \\
\hline $\mathrm{BI} 3$ & 0.903 & & & & \\
\hline BI4 & 0.893 & & & & \\
\hline Conditional value & & 5.05 & 0.849 & 0.882 & 0.652 \\
\hline CV1 & 0.794 & & & & \\
\hline CV2 & 0.732 & & & & \\
\hline $\mathrm{CV} 3$ & 0.806 & & & & \\
\hline $\mathrm{CV} 4$ & 0.890 & & & & \\
\hline Emotional value & & 5.55 & 0.899 & 0.937 & 0.832 \\
\hline EMV1 & 0.915 & & & & \\
\hline EMV2 & 0.932 & & & & \\
\hline EMV4 & 0.889 & & & & \\
\hline Epistemic value & & 5.70 & 0.925 & 0.941 & 0.727 \\
\hline EV1 & 0.823 & & & & \\
\hline
\end{tabular}




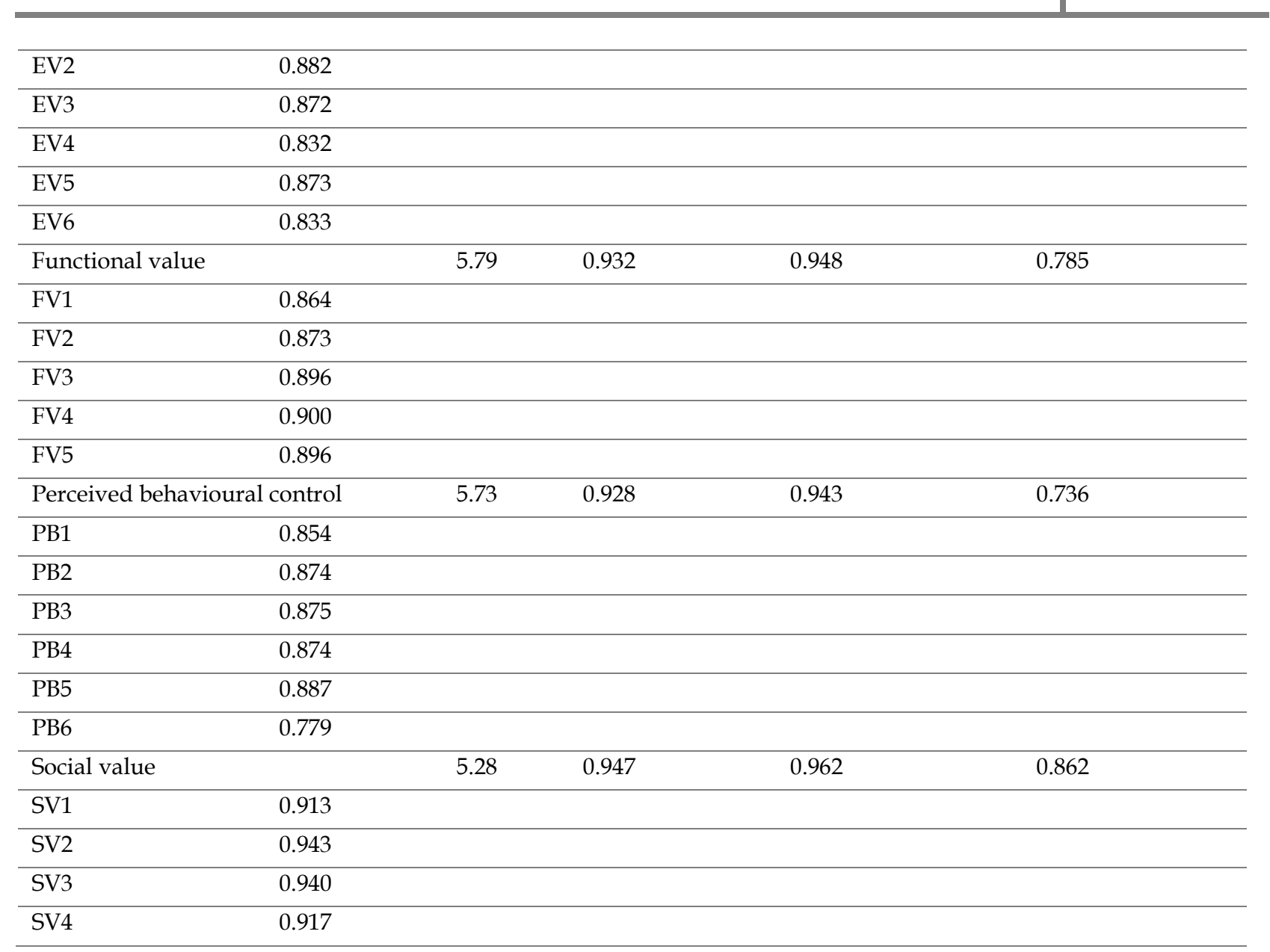

Table 3: Test of Discriminant Validity

\begin{tabular}{llllllllll}
\hline & 1 & 2 & 3 & 4 & 5 & 6 & 7 & 8 & 9 \\
\hline Adoption behaviour & 0.962 & & & & & & & & \\
\hline Attitude & 0.356 & 0.898 & & & & & & & \\
\hline Behavioural intention & 0.360 & 0.792 & 0.909 & & & & & & \\
\hline Conditional value & -0.019 & 0.345 & 0.327 & 0.808 & & & & & \\
\hline Emotional value & 0.246 & 0.778 & 0.754 & 0.360 & 0.912 & & & & \\
\hline Epistemic value & 0.326 & 0.752 & 0.734 & 0.337 & 0.729 & 0.853 & & & \\
\hline Functional value & 0.437 & 0.776 & 0.757 & 0.280 & 0.670 & 0.721 & 0.886 & & \\
\hline Perceived behavioural control & 0.371 & 0.781 & 0.773 & 0.359 & 0.764 & 0.720 & 0.798 & 0.858 & \\
\hline Social value & 0.255 & 0.716 & 0.712 & 0.379 & 0.770 & 0.725 & 0.627 & 0.709 & 0.929 \\
\hline
\end{tabular}

Note: Square root of AVE reflected diagonally

Table 2 shows that the respondents agreed to statements measuring the constructs with the means all above 5 on a 7-point Likert scale. The Cronbach's alpha and composite reliability scores for the constructs were all above the minimum threshold of 0.70, as recommended by Hair, Hult, Ringle and Sarstedt (2017). Composite trait reliability was therefore confirmed. Factor loadings for all 45 items varied between 0.732 and 0.945 . The AVE value for each of the constructs was above the recommended 0.5 (Hair et al., 2017). Convergent validity was therefore confirmed. The discriminant validity was assessed by determining whether the square root of the AVEs exceeded the corresponding inter-construct correlations and according to Fornell-Larcker's criterion (Hair et al., 2017). It is evident from Table 3 that this was indeed the case. Therefore, discriminant validity was confirmed. 


\subsection{Structural model: Hypothesis testing}

Table 4 below present the results of the tested hypotheses.

Table 4: Summary of Structural Model Analysis

\begin{tabular}{|c|c|c|c|c|c|c|}
\hline & $\begin{array}{l}\text { Path } \\
\text { coefficient }\end{array}$ & $\begin{array}{l}\mathrm{T} \\
\text { Statistics }\end{array}$ & $\begin{array}{l}\mathrm{P} \\
\text { Value }\end{array}$ & Result & $\mathrm{R}^{2}$ & $\mathrm{f}^{2}$ \\
\hline Functional value -> Attitude (H1) & 0.260 & 6.455 & 0.000 & Supported & \multirow[t]{5}{*}{$81 \%$} & 0.053 \\
\hline Emotional value -> Attitude (H2) & 0.301 & 5.826 & 0.000 & Supported & & 0.007 \\
\hline Conditional value -> Attitude (H3) & 0.026 & 1.550 & 0.121 & $\begin{array}{l}\text { Not } \\
\text { Supported }\end{array}$ & & 0.026 \\
\hline Epistemic value -> Attitude (H4) & 0.491 & 11.450 & 0.000 & Supported & & 0.170 \\
\hline Social value -> Attitude (H5) & -0.074 & 1.494 & 0.135 & $\begin{array}{l}\text { Not } \\
\text { Supported }\end{array}$ & & 0.006 \\
\hline $\begin{array}{l}\text { Social value -> Behavioural intention } \\
(\mathrm{H} 6)\end{array}$ & 0.093 & 2.539 & 0.011 & Supported & \multirow[t]{3}{*}{$83.4 \%$} & 0.153 \\
\hline Attitude -> Behavioural intention (H7) & 0.510 & 7.912 & 0.000 & Supported & & 0.297 \\
\hline PBC -> Behavioural intention (H8) & 0.358 & 5.781 & 0.000 & Supported & & 0.196 \\
\hline PBC -> Adoption behaviour (H9) & 0.242 & 3.344 & 0.001 & Supported & \multirow[t]{2}{*}{$24.3 \%$} & 0.025 \\
\hline $\begin{array}{l}\text { Behavioural intention } \rightarrow \text { Adoption } \\
\text { behaviour }(\mathrm{H} 10)\end{array}$ & 0.148 & 1.998 & 0.046 & Supported & & 0.118 \\
\hline
\end{tabular}

Table 4 shows that South African black middle-class consumers' attitudes toward green appliances were positively and significantly influenced by the functional value, emotional value, and epistemic value. Hence $\mathrm{H}_{1}, \mathrm{H}_{2}$ and $\mathrm{H}_{4}$ were supported. Conditional value and social value did not significantly influence attitude. Consequently, $\mathrm{H}_{3}$ and $\mathrm{H}_{5}$ could not be accepted. The five values explained $81 \%$ of the variance in attitude.

Attitude, social value and PBC positively and significantly impacted behavioural intention, explaining $83.4 \%$ of it. Thus, $\mathrm{H}_{6}, \mathrm{H}_{7}$ and $\mathrm{H}_{8}$ were accepted. Behavioural intention and $\mathrm{PBC}$ positively and significantly influenced the adoption of green appliances and explained $24.3 \%$ of it. Therefore, $\mathrm{H}_{9}$ and $\mathrm{H}_{10}$ were supported.

The $\mathrm{f}^{2}$ effect size (also known as R-square change effect) is a measure that calculates changes in the $\mathrm{R}^{2}$ should a specific exogenous construct be omitted from the model (Garson, 2016). $\mathrm{f}^{2}$ values of 0.02, 0.15 and 0.35 respectively were used as guidelines for small, medium, and large effect sizes of the predictive variables (Cohen, 1988). As shown in Table 4, we found a small effect of functional value and conditional value and a very small effect of emotional value and social value on attitudes. Epistemic value was found to have a medium effect on attitudes. Attitudes, social value, and perceived behavioural control were found to also have a medium effect on behavioural intention. Lastly, the results showed that perceived behavioural control and behavioural intention had a small effect on adoption behaviour.

The final step in assessing the structural model was to assess the predictive relevance of the three endogenous constructs (attitudes, behavioural intention, and adoption behaviour) using Stone-Geisser's Q2 statistic (Geisser, 1975; Stone, 1974). SEM-PLS requires a measure of predictive capability which uses an approach known as the 'blindfolding procedure'. A cross-validated redundancy greater than 0 shows that there is predictive relevance while a value less than 0 indicates that the model lacks predictive relevance (Chin, 1998). In this study, the model was found to have predictive relevance, as the crossvalidated redundancy result (the Stone-Geisser test $\mathrm{Q}^{2}$ ) was 0.653 (attitude), 0.645 (behavioural intention) and 0.165 (adoption behaviour), all of which are greater than 0 .

\section{Discussion and implications}

The adoption of non-conventional and sustainable products such as green appliances, which are often perceived to be more expensive, requires the integration of theories to gain a richer understanding of attitudes and behaviour drivers. Considering that about $80 \%$ of South-African middle class uses appliances, this study integrated two theories (TCV and TPB) to examine the drivers of black middle-class consumers' attitudes, behavioural intention, and adoption of green appliances. It was found that black 
middle-class consumers not only held strong positive attitudes towards green appliances, but $50 \%$ had in fact purchased such appliances. The positive attitude was driven by functional, emotional, and epistemic benefits (values) expected from the appliances.

Epistemic value $(\beta=0.491)$ made the greatest contribution to attitude formation. This result supports the findings of Barber et al. (2014) in the USA and Biswas and Roy (2015) in India who also found that the quest for novelty and knowledge about a product (epistemic value) were among the top drivers of green product interest. Other studies (Chen and Chang, 2012; Suki, 2013) have found that functional value was the important player in stimulating green product purchase intentions. It was encouraging to note that emotional value, which Koenig-Lewis et al. (2014) describe as the intrinsic feelings of doing something good both for one's wellbeing and that of the environment, influenced South African black middle class consumers' green appliances attitudes. This finding supports the results of Koenig-Lewis et al. (2014) which showed that Norwegian consumers' BI to buy beverages packaged with organic material was influenced by emotional value. There is a saying in South Africa that if you feel good about something, you do good about that thing'. If a large and influential market segment such as the South African black middle class were to develop positive attitudes about green appliances because they felt good about them, the demand for sustainable products would grow. This would greatly reduce energy and water consumption in the country, which is currently a cause for concern.

It was, however, worrying to find in this study that conditional value, which includes the wellknown threat of resource depletion in South Africa - did not significantly influence the country's large middle-class consumers' attitudes towards green appliances. Considering the ongoing water and electricity shortages in South Africa, it was expected that conditional value would strongly trigger consumers' green appliance attitudes, as found by Gadenne et al. (2011) in Australia. However, in India, an emerging economy such as South Africa, Biswas, and Roy (2015) also failed to validate the relationship between conditional value and green product interest.

Even though green consumption is often viewed as an altruistic act, Arruda-Filho, Cardoso and Barboza (2019) expressed concern that pro-environmental actions (e.g., taking public transport to save fuel, car and parking costs instead of reducing carbon emission) may be done for selfish or individualistic reasons. Conditional values are more related to environmental values (Sangroya and Nayak, 2017). The extent to which emerging market consumers feel good about green products for their personal cost savings and interests (emotional and functional values) and are happy that they own a new innovation (epistemic value), may indicate that they are individualistically motivated to buy green appliances. This assumption stems from the fact that functional, emotional, and epistemic values may be related more with personal values than altruistic ones (Arruda-Filho et al., 2019). This, however, needs empirical confirmation by studying the strength of emerging market consumers' environmental and altruistic values. Nonetheless, the positive attitudes towards green appliances derived from functional, epistemic, and emotional values are good news for marketers. Zhang et al. (2020) suggest that two of these values (functional and emotional) impact willingness to pay the premium price associated with green appliances.

This study found a negative relationship between social value and attitudes, even though this relationship was not significant. This means that even though previous studies have pointed to social pressures and peer opinion as important drivers of green purchase decision-making (Dhurup, 2012; Wahid et al., 2011), for South African middle class consumers, social pressures and opinions appear to be rather demotivating, although not significantly. This could be another indication that the consumers in this study held favourable attitudes towards green appliances for personal as opposed to social reasons.

The social pressure and opinions in our finding, together with developed attitude and PBC, significantly impacted BI. This finding is corroborated by Chekima, Wafa, Igau, Chekima and Sondoh (2016), Lorek and Fuchs (2013) and Wang et al. (2014). Our findings validate the TPB in explaining green product BI in a multicultural and socio-demographically diverse country like South Africa. It can therefore be contended that individuals who hold positive attitudes, experience social benefits, and have favourable PBC are more likely to engage in sustainable behaviour. The likelihood of performing the sustainable behaviour can be better explained if the TCV is also incorporated into the TPB, as done in the current study. Our integration of the TPB and TCV explained a greater percentage (83.4\%) of BI compared to Lin and Huang (2012) and Taylor (2015), who could only explain $48 \%$ and $26.7 \%$ of BI respectively, 
using a single theory. Thus, to increase the BI propensity of the large and profitable black middle class, marketers and environmental practitioners should start by promoting the consumption values to be gained from such products. This would enhance positive attitudes by $81 \%$ and BI by $83.4 \%$, as proven in this study. Thus, while PBC, attitudes and subjective norms are important BI drivers (as posited by the TPB), we show that consumption values are also important in boosting BI. These findings not only shed light on drivers of green product consumption, but they also provide insights into the black middle class, which is a large, lucrative, and fast-growing market segment in South Africa.

The integration of the TPB and TCV explained only $24.3 \%$ of actual adoption. This suggests that in addition to BI and PBC, which significantly influenced actual adoption in this study, there are other factors that can translate BI into action. These could be marketing factors in terms of creating awareness of the benefits of green appliances, reasonable pricing and the promotion of the good price, especially since green products are perceived to be more expensive (Barber et al., 2014; Biswas and Roy, 2015) as well as the wider distribution and availability of the products. Other factors that can translate BI into actual adoption could be regular in-store training and even demonstrations of the relative advantage, lower complexity and greater compatibility of green appliances compared to conventional ones. These factors and perceived cost could - according to DOI theory - increase adoption rates. Future studies should therefore integrate the DOI for a three-theory explanation of green appliance adoption. While our twotheory model greatly explained BI and can be a good framework to explain BI for other proenvironmental products in other emerging markets, the suggested three-theory model could improve the explanation of actual adoption, which is rarely studied.

\section{Research limitations and future research opportunities}

Notwithstanding the contributions of this study, there are several limitations which could be addressed in future studies.

The sample used for this study was selected from only one geographical area, namely, the Gauteng Province in South Africa. Gauteng houses the country's economic capital (Johannesburg) and political capital (Pretoria). It also has the highest proportion of people classified as black middle class. However, the findings could be better generalised if black middle-class consumers were studied in other, less affluent provinces.

Even though various demographic characteristics of the black middle class were considered, future studies could use bigger sample sizes for better generalisation.

Using structured questionnaires may have limited respondents' views on the consumption values they expected and enjoyed from green appliances. A qualitative design through in-depth interviews and focus groups could provide other insights into consumption values and drivers of attitude and green appliance behaviour.

Even though behavioural intention influenced actual adoption in the current study, further research is needed to identify factors that would better close the gap between intention and actual behaviour. Given the importance of environmental sustainability, it is necessary to understand which factors can influence consumers to purchase green appliances and to improve the variance explained in actual adoption.

\section{Conclusion}

Water and electricity shortages are becoming more frequent in South Africa. Such shortages could be mitigated if the country's black middle-class consumers, most of whom own appliances, were to adopt green ones. This study thus assessed attitude towards green appliances and their adoption. The study also integrated the TPB and TCV to examine drivers of attitude, BI and actual adoption. The integrated theoretical model explained high percentages of attitude and BI compared to previous studies that used only a single theory. However, the integrated model provided a weak explanation of actual adoption, thus suggesting the extension of the model to include other constructs or theories.

In addition to the theoretical contribution of this study, especially in the area of sustainable consumer behaviour, this study provides marketers, environmental interest groups and policy makers with valuable insights which could be used to tailor messages to persuade South Africa's large and 
lucrative black middle class to start and continue using green appliances. Future studies could assist by identifying other factors that can translate BI into actual adoption.

\section{References}

Ajzen, I. (1991). The theory of planned behaviour. Organizational Behaviour and Human Decision Processes, 50(2), pp. $179-211$.

Ajzen, I. (2005). Attitudes, personality, and behavior. London: McGraw-Hill Education.

Albayrak, T., Aksoy, Ş. \& Caber, M. (2013). The effect of environmental concern and scepticism on green purchase behaviour. Marketing Intelligence \& Planning, 31(1), pp. 27-39.

Albrecht, C., Backhaus, C., Gurzki, H. \& Woisetschlager, D.M. (2013). Drivers of brand extension success: What really matters for luxury brands. Psychology and Marketing, 30(8), pp. 647-659.

Arruda-Filho, E.J.M., Cardoso, B.L. \& Bardoza, M.N.L. (2019). Intention of green consumption in the context of the selfish or altruistic features of the product versus the user's environmental consciousness. Cadernos EBAPE.BR, 17(2), pp. 414-434.

Barber, N.A., Bishop, M. \& Gruen, T. (2014). Who pays more (or less) for pro-environmental consumer goods? Using the auction method to assess actual willingness-to-pay. Journal of Environmental Psychology, 40, pp. 218-227.

Bartels, J. \& Reinders, M. J. (2010). Social identification, social representations and consumer innovativeness in an organic food context: A cross-national comparison. Food Quality and Preference, 21, pp. 347-352.

Biswas, A. \& Roy, M. (2015). Leveraging factors for sustained green consumption behaviour based on consumption value perceptions: testing the structural model. Journal of Cleaner Production, 95, pp. 332-340.

Chekima, B., Wafa, S.A.W.S.K., Igau, O.A., Chekima, S. \& Sondoh, S.L. (2016). Examining green consumerism motivational drivers: does premium price and demographics matter to green purchasing? Journal of Cleaner Production, 112, pp. 3436-3450.

Chen, K.K. (2014). Assessing the effects of customer innovativeness, environmental value and ecological lifestyle on residential solar power systems install intention. Energy Policy, 67(1), pp. 951-961.

Chen, A. \& Peng, N. (2012). Green hotel knowledge and tourists' staying behaviour. Annals of Tourism Research, 39, pp. 2203-2219.

Chen, M.F. \& Tung, P.J. (2014). Developing an extended theory of planned behavior model to predict consumers' intention to visit green hotels. International Journal of Hospitality Management, 36, pp. 221-230.

Chen, Y.S. \& Chang, C.-H. (2012). Enhance green purchase intentions. The roles of green perceived value, green perceived risk, and green trust. Journal of Management Decisions, 50(3), pp. 502-520.

Cherian, J. \& Jacob, J. (2012). Green marketing: a study of consumers' attitude towards environment friendly products. Asian Social Sciences, 8, pp. 117-126.

Chin, W. W. (1998). Issues and opinion on structural equation modeling. MIS Quarterly, 22(1), pp. 7-16.

Choi, D. \& Johnson, K.K.P. (2019). Influences of environmental and hedonic motivations on intention to purchase green products: An extension of the theory of planned behaviour. Sustainable Production and Consumption, 18, pp. 145-155.

Cohen, J. (1988). Statistical power analysis for the behavioral sciences (2nd ed.). Hillsdale, NJ: Lawrence Erlbaum Associates.

Dhurup, M. (2012). Victory may have a thousand supporters, but defeat may have none: Effects of team identification on BIRGing and CORFing, satisfaction and future behavioural intentions. African Journal for Physical, Health Education, Recreation and Dance, 18(4), pp. 742-758.

Euromonitor International. (2013) Consumer appliances in South Africa. Available at:

http://www.euromonitor.com. (Accessed 28 August 2017).

Faure, C. \& Schleich, R. (2020). Poor energy ratings when appliances convey? Energy Policy, 139, pp. 1-8.

Gadenne, D., Sharma. B., Kerr, D. \& Smith T. (2011). The influence of consumers' environmental beliefs and attitudes on energy savings behaviours. Energy Policy, 39, pp. 7684-7694.

Garson, G. D. (2016). Partial Least Squares: Regression and Structural Equation Models. Asheboro, NC: Statistical Associates Publishers.

Geisser, S. (1975). The predictive sample reuse method with applications. Journal of the American Statistical Association, 70(350), pp. 320-328.

Ha, H.-Y. \& Janda, S. (2012). Predicting consumer intentions to purchase energy-efficient products. Journal of Consumer Marketing, 29(7), pp. 461-469.

Hair, J.F., Hult, G.T.M., Ringle, C.M. \& Sarstedt, M. (2017). A Primer on Partial Least Squares Structural Equation Modeling. 2nd ed. Thousand Oaks, CA: Sage.

Hawkins, D. \& Tull, D. (1993). Marketing Research, Measurements and Methods: A Test with Cases. London: Macmillan Publishing. 
Huang, H.C., Lin, T.H., Lai, M.C. \& Lin, T.L. (2014). Environmental consciousness and green customer behavior: an examination of motivation crowding effect. International Journal of Hospitality Management, 40, pp. 139-149.

Jamilah, A., Ali, I., Grigore, G. F. \& Stancu, A. (2012). Studying consumers' ecological consciousness: A comparative analysis of Romania and Pakistan. Amfiteatru Economic, 14, pp. 84-98.

Kanchanapibul, M., Lacka, E., Wang, X. \& Chan, H. K. (2014). An empirical investigation of green purchase behaviour among the young generation. Journal of Cleaner Production, 66, pp. 528-536.

Kim, H.Y. \& Chung, J.E.C. (2011). Consumer purchase intention for organic personal care products. Journal of Consumer Marketing, 28(1), pp. 40-47.

Kline, R.B. (2011). Principles and practice of structural equation modelling. New York: Guilford Press.

Koenig-Lewis, N., Palmer, A., Dermody, J. \& Urbye, A. (2014). Consumers' evaluations of ecological packaging: Rational and emotional approaches. Journal of Environmental Psychology, 1, pp. 1-55.

Kroeker, L.L. (2014). Kenya's emerging middle class(es). European Association of Development Research and Training Institute, pp. 1-12.

Lai, C.K.M. \& Cheng, E.W.L. (2016). Green purchase behaviour of undergraduate students in Hong Kong. The Social Science Journal, 53, pp. 67-76.

Laurenti, R. \& Acuna, F.M.B. (2020). Exploring antecedents of behavioural intention and preferences in online peer-topeer resource sharing: A Swedish university setting. Sustainable Production and Consumption, 21, pp. 47-56.

Liao, X., Shen, S.V. \& Shi, X. (2020). The effects of behavioral intention on the choice to purchase energy-saving appliances in China: the role of environmental attitude, concern, and perceived psychological benefits in shaping intention. Energy Efficiency, 13, pp. 33-49.

Lin, P.C. \& Huang, Y.H. (2012). The influence factors on choice behaviour regarding green products based on the theory of consumption values. Journal of Clean Production, 22, pp. 11-18.

Lorek, S. \& Fuchs, D. (2013). Strong sustainable consumption governance precondition for de-growth path? Journal of Cleaner Production, 38, pp. 36-43.

Maheshwari, A. \& Malhotra, G. (2011). Green marketing: a study on Indian youth. International Journal of Management Strategy, 2(3), pp. 31-46.

Matthes, J., Wonneberger, A. \& Schmuck, D. (2014). Consumers' green involvement and the persuasive effects of emotional versus functional ads. Journal of Business Research, 67, pp. 1885-1893.

Moser, A.K. (2015). Thinking green, buying green? Drivers of pro-environmental purchasing behaviour. Journal of Consumer Marketing, 32(3), pp. 167-175.

Mostafa, M.M. (2009). Shades of green: a psychographic segmentation of the green consumer in Kuwait using selforganizing maps. Expert Systems Application, 36, pp. 11030-11038.

Podsakoff, P.M., MacKenzie, S.B., Lee, J.Y. \& Podsakoff, N.P. (2003). Common method biases in behavioural research: a critical review of the literature and recommended remedies. Journal of Applied Psychology, 88(5), pp. 879-903.

Pothitou, M., Kolios, A.J., Varga, L. \& Gu, S. (2016). A framework for targeting household energy savings through habitual behavioural change. International Journal of Sustainable Energy, 35(7), pp. 686-700.

Sangroya, D. \& Nayak, J.K. (2017). Factors influencing buying behaviour of green energy consumer. Journal of Cleaner Production, 151, pp. 393-405.

Saunders, M., Lewis, P. \& Thornhill, A. (2012). Research Methods for Business Students. 6th ed. London: Pearson.

Sheth, J.N., Newman, B.I. \& Gross, B.L. (1991). Why we buy what we buy: a theory of consumption values. Journal of Business Research, 22(2), pp. 159-170.

Smil, V. (2013). Harvesting the Biosphere: What We Have Taken from Nature. Cambridge, MA: MIT Press.

Sonnenberg, N.C., Erasmus, A.C. \& Schreuder, A. (2014). Consumers' preferences for eco-friendly appliances in an emerging market context: a conjoint and cluster analysis. International Journal of Consumer Studies, 38, pp. 559569.

Steyn, L. (2013). March of the black middle class has promising spin-offs. Available at:

http:/ / mg.co.za/article/2013-05-03-00-march-of-the-black-middle-class-has-promising-spin-offs. (Accessed 9 August 2017).

Stone, M. (1974). Cross-validatory choice and assessment of statistical predictions. Journal of the Royal Statistical Society, 36(2), pp. 111-147.

Suki, N.M. (2013). Young consumer ecological behaviour: effects of environmental knowledge, healthy food, and healthy way of life with the moderation of gender and age. International Journal of Management Environmental Quality, 24, pp. 726-737.

Sweeney, J.C. \& Soutar, G. N. (2001). Consumer perceived value: The development of a multiple item scale. Journal of Retailing, 77(2), pp. 203-220.

Tan, L., Johnstone, M.L. \& Yang, L. (2016). Barriers to green consumption behaviours: The roles of consumers'green perceptions. Australasian Marketing Journal, 22(4), pp. 288-299. 
Teng, W. (2019) Utilitarian, hedonic, collecting, epistemic, and high values as determinants of the attractiveness of premium promotions. Journal of Marketing Communications, 25(6), pp. 626-644.

Tsay, Y.Y. (2010). The Impact of Economic Crisis on Green Consumption in Taiwan. In: Portland International Conference in Management of Engineering and Technology (PICMET). Taiwan, pp. 2367-2374.

United Nations Environment Program (UNEP). (2011). South Africa's Pathway to a Green Economy. [online] Available at: http://www.unep.org/greeneconomy/portals/88/documents/advisory_services/South\%20Afric a.pdf (Accessed 3 December 2015).

United Nations Environment Programme (UNEP). (2014). New Global Alliance for Energy-Efficient Appliances and Equipment Launched. [online] Available at: http://web.unep.org/newscentre/new-global-alliance-energyefficient-appliances-and-equipment-launched. (Accessed 5 December 2015).

United Nations Environment Programme (UNEP). (2015). Annual Report 2015. [online] Available at: https://www.unenvironment.org/annualreport/2015/en/index.html. (Accessed 18 July 2016).

University of Cape Town Unilever Institute of Strategic Marketing. (2016). 5 million and RISING Presentation. [online] Available at: http:/ / www.uctunileverinstitute.co.za/ (Accessed 15 December 2018).

Wahid, N.A., Rahbar, E. \& Shyan, T.S. (2011). Factors influencing the green purchase behaviour of Penang environmental volunteers. International Business Management, 5(1), pp. 38-49.

Wan, C., Cheung, R. \& Shen, G. (2012). Recycling attitude and behaviour in university campus: A case study in Hong Kong. Facilities, 30(13), pp. 630-646.

Wang, P., Liu, Q. \& Qi, Y. (2014). Factors influencing sustainable consumption behaviours: a survey of the rural residents in China. Journal of Cleaner Production, 63(15), pp. 143-151.

Woo, E. \& Kim, Y.G. (2019). Consumer attitudes and buying behavior for green food products: From the aspect of green perceived value (GPV). British Food Journal, 121(2), pp. 320-332.

Xiao, G. (2005). The Chinese consumers' changing value system, consumption values and modern consumption behaviour. PhD. Auburn University.

Yeow, P., Dean, A. \& Tucker, D. (2014). Bags for life: The embedding of ethical consumerism. Journal of Business Ethics, 125, pp. 87-99.

Zabkar, V. \& Hosta, M. (2013). Willingness to act and environmentally conscious consumer behaviour: Can prosocial status perceptions help overcome the gap? International Journal of Consumer Studies, 37(3), pp. 257-264.

Zhang, Y., Xiao, A. \& Zhou, G. (2020). Willingness to pay a price premium for energy-saving appliances: Role of perceived value and energy efficiency labelling. Journal of Cleaner Production, 242, pp. 1-12. 